\title{
Papers
}

\section{Effect on endometrium of long term treatment with continuous combined oestrogen-progestogen replacement therapy: follow up study}

\author{
Michael Wells, David W Sturdee, David H Barlow, Lian G Ulrich, Karen O’Brien, Michael J Campbell, \\ Martin P Vessey, Anthony J Bragg, for the UK Continuous Combined Hormone Replacement \\ Therapy Study Investigators
}

\begin{abstract}
Objective To determine effects of five years of treatment with an oral continuous combined regimen of $2 \mathrm{mg} 17 \beta$-oestradiol and $1 \mathrm{mg}$ norethisterone acetate on endometrial histology in postmenopausal women.

Design Follow up study in postmenopausal women. Setting 31 menopause clinics in the United Kingdom. Participants 534 postmenopausal women, all with an intact uterus, who had completed nine months of treatment with oral continuous combined $2 \mathrm{mg}$ $17 \beta$-oestradiol and $1 \mathrm{mg}$ norethisterone acetate agreed to take part in a long term follow up study. Women were assigned to different groups on the basis of the treatment status immediately before entering the original study: 360 women had taken sequential oestrogen-progestogen hormone replacement therapy, 164 had taken no hormone replacement therapy, and 10 had taken unopposed oestrogen therapy.

Methods Endometrial aspiration specimens were taken before the women started the continuous combined regimen, after 9 and 24-36 months, and at the end of the five year treatment period or on withdrawal from the study.

Main outcome measure Results of endometrial histology.

Results The duration of treatment with continuous combined hormone replacement therapy was 4.4 (range 1.1-5.9) years. Data on endometrial specimens were available for 526 women after nine months of treatment, 465 women after 24-36 months of treatment, and 398 women who completed the five years treatment (345 women) or were withdrawn between the two latter visits for biopsies (53 women). No cases of endometrial hyperplasia or malignancy were detected at biopsy; $69 \%$ of women had an endometrium classified as atrophic or unassessable on completion of the study or withdrawal from it. Before the continuous combined therapy was started, complex hyperplasia was detected in 21 women who had taken sequential hormone replacement therapy before the study and in one who had taken unopposed oestrogen. All of these women had
\end{abstract}

normal results on histological examination of endometrial tissue after nine months of treatment with continuous combined hormone replacement therapy, and hyperplasia did not recur after up to five years of treatment.

Conclusions Long term treatment (for up to five years) with continuous combined hormone replacement therapy containing oestradiol $2 \mathrm{mg}$ and norethisterone $1 \mathrm{mg}$ daily was associated with neither endometrial hyperplasia nor malignancy. In women who had complex hyperplasia during previous sequential or unopposed regimens, the endometrium returned to normal during treatment with continuous combined hormone replacement therapy. These findings provide reassurance about the long term safety of this continuous combined regimen in terms of the endometrium.

\section{Introduction}

We reported an increased prevalence of complex endometrial hyperplasia in postmenopausal women receiving standard sequential oestrogen-progestogen hormone replacement therapy compared with those receiving no hormone replacement therapy. ${ }^{12}$ Other studies reported an increased risk of endometrial carcinoma in women who used such treatments over long periods compared with those who did not. ${ }^{3}$ Information about the safety of standard sequential oestrogen-progestogen hormone replacement therapy used over long periods, along with a lack of compliance because of withdrawal bleeding, has highlighted the need for alternative types of hormone replacement therapy. ${ }^{56}$

Continuous combined hormone replacement therapy, in which oestrogen and progestogen are given together daily, is being used more often. Such regimens avoid the cyclical problems associated with sequential therapy in most women and combine protection of the endometrium with amenorrhoea, so that compliance improves. ${ }^{7-11}$ Safety data about such regimens are needed if long term treatment is to be recommended, but such data are limited. Data that are available have looked at periods of use only up to three years. ${ }^{12}{ }^{13}$ \begin{tabular}{ll}
\hline Editorial by Archer & \\
\cline { 1 - 1 } &
\end{tabular} 
School of Health and Related Research,

Community

Sciences Centre,

Northern Genera

Hospital, Sheffield

S5 $7 \mathrm{AU}$

Michael J Campbell

professor

Department of

Public Health,

Institute of Health

Sciences, Oxford

OX3 7LF

Martin P Vessey

professor

Correspondence to:

M Wells

m.wells@sheffield.

ac.uk
Box 1 Classification and associated features of histological examination of endometrial tissue

Unassessable

- No tissue identified

- Tissue insufficient for diagnosis

- No endometrium identified

- Endometrial tissue insufficient for diagnosis

Inactive

- Narrow tubular glands lined with cuboidal

epithelium

Atrophic

- Cystically dilated glands lined by single layer of inactive, flattened epithelial cells

Proliferative

- Presence of epithelial mitoses

Secretory

- Epithelial cytoplasmic vacuolation-subnuclear or supranuclear

- Glandular luminal secretion in mid-phase and late phase

Pseudo-decidual change

- Typical stromal decidual change associated with inactive or weakly secretory glands, induced by progestogen

Simple hyperplasia

- Dilated glands with increased nuclear stratification of lining epithelium and increased stromal mitoses

- No risk of malignancy

Complex hyperplasia

- Crowded and irregular branched glands

- Low risk of malignancy

Atypical hyperplasia (intraendometrial neoplasia)

- Atypical epithelial cells; high risk of malignancy

The endometrium becomes atrophic within six months of women starting continuous combined hormone replacement therapy containing $2 \mathrm{mg} 17 \beta-$ oestradiol and $1 \mathrm{mg}$ norethisterone acetate. ${ }^{14-16} \mathrm{In}$ many cases, the endometrium cannot be assessed because biopsy specimens contain insufficient tissue. ${ }^{2}{ }^{17}$ Continuous combined hormone replacement therapy stops bleeding in most postmenopausal women, ${ }^{214-16}$ and it may transform hyperplastic endometrium into states of atrophy after three to nine months. ${ }^{28}$

We investigated the effects of continuous combined hormone replacement therapy containing $2 \mathrm{mg}$ $17 \beta$-oestradiol and $1 \mathrm{mg}$ norethisterone acetate on endometrial histology and bleeding patterns in postmenopausal women treated for up to five years. As far as we are aware, this is the largest long term study of its kind, reporting data from 534 women.

\section{Methods}

An open, prospective, multicentre British study investigated women treated with a continuous combined hormone replacement therapy regimen containing $2 \mathrm{mg} 17 \beta$-oestradiol and $1 \mathrm{mg}$ norethisterone acetate (Kliofem, Novo Nordisk; Kliogest outside the United
Kingdom) for nine months. ${ }^{2}$ The study was conducted at 54 menopause clinics. When the study ended, we recruited women who had completed the treatment period and who elected to continue the treatment for up to five years into a long term follow up study. The five year follow up included the nine months of the original study. Women were recruited from 31 of the clinics (29 based in hospitals; two in general practice) that participated in the original trial.

The follow up study was approved by local ethics committees, and it was conducted in accordance with the Declaration of Helsinki (Hong Kong revision, 1989). All women gave written, informed consent to participate.

We took endometrial aspiration biopsies before continuous combined hormone replacement therapy was started, after nine and 24-36 months of treatment, and after five years of treatment or withdrawal from the study. Biopsy specimens were taken in outpatient clinics, using Pipelle de Cornier samplers (Eurosurgical, Guildford). ${ }^{18}$ Samples were fixed in $4 \%$ unbuffered formalin and processed routinely. A single independent pathologist (MW), who was blind to any details of the patients, assessed the histological samples and classified them according to standard criteria (box 1). We used frequency counts to summarise the results of endometrial biopsies for each type of response. Other data were summarised with appropriate summary statistics.

\section{Results}

Overall, 534 women provided data for the follow up study. Before the original study, 360 women had taken sequential hormone replacement therapy, 164 no hormone replacement therapy, and 10 unopposed oestrogen. The characteristics were similar for women from the different treatment regimens, so the data were pooled (table 1). The mean duration of treatment with continuous combined hormone replacement therapy was 4.4 (range 1.1-5.9 months).

Data about endometrial biopsies were available for 531 women before treatment (table 2), 526 women after nine months of continuous combined hormone replacement therapy (as part of the original study period), 465 (87\%) women after 24-36 months (table $3)$, and $398(75 \%)$ women after 5 years of treatment (345 women) or on withdrawal (53 women). No cases of endometrial hyperplasia or malignancy were detected in women whose biopsy specimens were assessable. Most specimens in the "other" category were benign endocervical or endometrial polyps (figure).

Table 1 Characteristics of 534 women in study of continuous combined hormone replacement therapy

\begin{tabular}{lc} 
Characteristic & Mean (SD; range) \\
\hline Age at start of treatment (years) & $54.2(5.2 ; 40-73)$ \\
\hline Age at menopause (years) ${ }^{*}$ & $47(5 ; 18-57)$ \\
\hline Height $(\mathrm{cm})$ & $161.6(6.2 ; 140-184)$ \\
\hline Weight $(\mathrm{kg})$ & $65.7(10.7 ; 41.6-108)$ \\
\hline Duration of treatment (years) $\dagger$ & $4.4(1 ; 1.1-5.9)$
\end{tabular}

†10 missing values; all other variables had a maximum of two missing values. Three women received treatment for more than five years; one of these received treatment for 5.9 years. 
Table 2 Number (\%) of women with different histological classifications of endometrial tissue before treatment with continuous combined hormone replacement therapy

\begin{tabular}{|c|c|c|c|c|}
\hline \multirow[b]{2}{*}{ Classification } & \multicolumn{3}{|c|}{ Previous hormone replacement therapy } & \multirow[b]{2}{*}{ Total } \\
\hline & None $(n=164)$ & Sequential $(n=360)$ & Unopposed oestrogen $(n=10)$ & \\
\hline Unassessable & $76(46)$ & $45(13)$ & $5(50)$ & $126(24)$ \\
\hline Inactive or atrophic & $68(41)$ & $32(9)$ & $0(0)$ & $100(19)$ \\
\hline Proliferative & $3(2)$ & $62(17)$ & $1(10)$ & $66(12)$ \\
\hline Secretory & $14(9)$ & $180(50)$ & $3(30)$ & $197(37)$ \\
\hline Pseudo-decidual & 0 & $4(1)$ & 0 & $4(1)$ \\
\hline Menstrual & 0 & $6(2)$ & 0 & $6(1)$ \\
\hline Complex hyperplasia & 0 & $21(6)$ & $1(10)$ & $22(4)$ \\
\hline Atypical hyperplasia & 0 & 0 & 0 & 0 \\
\hline Carcinoma & 0 & 0 & 0 & 0 \\
\hline Other & $2(1)$ & $8(2)$ & 0 & $10(2)$ \\
\hline Missing & $1(1)$ & $2(1)$ & 0 & $3(1)^{*}$ \\
\hline
\end{tabular}

*Includes two patients who completed the follow up study and one patient who was withdrawn.

Complex hyperplasia was detected in 21 women who had been taking sequential hormone replacement therapy and one woman who had been taking unopposed oestrogen before the study (table 2). Sixteen of these women completed five years of treatment with continuous combined hormone replacement therapy and six withdrew from the study. In all 22 cases, the complex hyperplasia reverted to normal endometrial patterns after nine months of treatment, ${ }^{2}$ and hyperplasia had not recurred by completion of or withdrawal from the study (table 4). We did not analyse other possible changes in histology from one category of normal histology to another during the study.

\section{Discussion}

No cases of endometrial hyperplasia or malignancy occurred during the five years of the study. We previously showed that all women who had complex hyperplasia while taking previous sequential or unopposed hormone replacement therapy reverted to normal after nine months of continuous combined hormone replacement therapy. ${ }^{2}$ The current study showed that hyperplasia did not recur and that new cases did not develop in women treated for up to five years. The results give reassurance about the long term endometrial safety of this regimen.

\section{Strengths and weaknesses of the study}

Most previous long term studies involved small numbers of patients or a shorter duration of treatment,

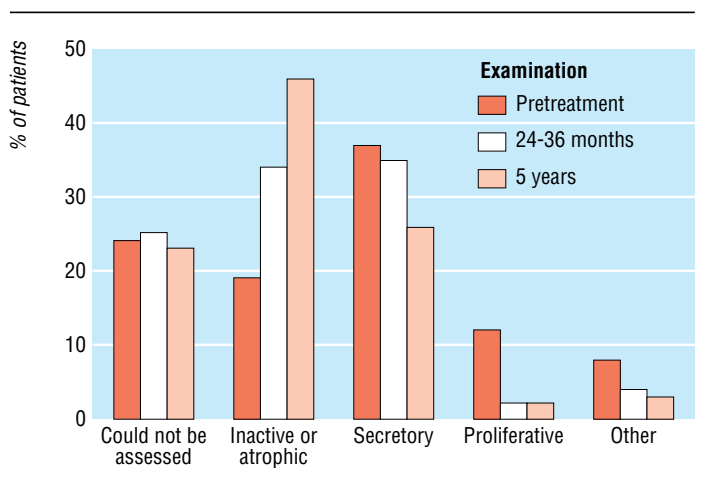

Results of histological examination of endometrium from women treated for up to five years with continuous combined hormone replacement therapy or both. . $-1012131719^{19}$ This study confirms that long term treatment for up to five years with a continuous combined hormone replacement therapy regimen of oestradiol $2 \mathrm{mg}$ and norethisterone acetate $1 \mathrm{mg}$ daily was associated with neither endometrial hyperplasia nor malignancy and that it converted the endometrium to normal in women in whom complex hyperplasia arose during previous sequential or unopposed oestrogen regimens.

\section{Strengths and weaknesses in relation to other} studies

Our results support the findings of previous studies with long term continuous combined hormone replacement therapy. ${ }^{9}{ }^{12}{ }^{13}$ Staland also found that the combination of oestradiol $2 \mathrm{mg}$ with norethisterone acetate $1 \mathrm{mg}$ was associated with reversion of pre-existing hyperplasia to normal endometrium. ${ }^{20} \mathrm{~A}$ recent population based study has reported that women taking continuous combined hormone replacement therapy did not seem to be at any increased risk of endometrial cancer relative to women who had never received hormone replacement therapy. ${ }^{21}$

Endometrial carcinoma has been reported only rarely in women taking continuous combined hormone replacement therapy regimens..$^{10}{ }^{192}$ In most cases the women had a history of unopposed oestrogen or of sequential use with less than 10 days of

Table 3 Number (\%) of women with different histological classifications of endometrial tissue after 24-36 months of treatment with continuous combined hormone replacement therapy and on completion of 5 years of treatment or withdrawal from study

\begin{tabular}{lcc} 
& \multicolumn{2}{c}{ Time endometrial sample taken } \\
\cline { 2 - 3 } Classification & At $\mathbf{2 4 - 3 6}$ months $(\mathbf{n}=\mathbf{4 6 5})^{*}$ & $\begin{array}{c}\text { On completion of } \mathbf{5} \text { years of } \\
\text { treatment } \text { or withdrawal }(\mathbf{n}=\mathbf{3 9 8})\end{array}$ \\
\hline Unassessable & $117(25)$ & $92(23)$ \\
\hline Inactive or atrophic & $157(34)$ & $185(46)$ \\
\hline Proliferative & $11(2)$ & $8(2)$ \\
\hline Secretory & $162(35)$ & $102(26)$ \\
\hline Pseudo-decidual & $8(2)$ & $5(1)$ \\
\hline Menstrual & 0 & 0 \\
\hline Complex hyperplasia & 0 & 0 \\
\hline Atypical hyperplasia & 0 & 0 \\
\hline Carcinoma & 0 & 0 \\
\hline Other & $10(2)$ & $6(2)$
\end{tabular}

*307 had received sequential hormone replacement therapy, 150 no previous hormone replacement therapy, and eight unopposed oestrogen.

†263 had received sequential hormone replacement therapy, 127 no previous hormone replacement therapy, and eight unopposed oestrogen. 
progestogen, risk factors such as a family history of endometrial carcinoma, or an inadequate dose of progestogen. ${ }^{23}$

The proportion of unassessable biopsies was lower than in previous studies of continuous combined hormone replacement therapy, in which more than $50 \%$ of biopsy specimens obtained from postmenopausal women did not have sufficient tissue for assessment. ${ }^{162425}$ A separate study of 40 postmenopausal women treated with the same drug at one of the participating sites confirmed that the Pipelle method of sampling was effective and that an unassessable specimen was associated with endometrial atrophy. ${ }^{26}$

Most studies did not identify the proportion of endometrial biopsies with secretory or proliferative changes but classified such biopsies along with others in a normal category. A study by Nand et al in 568 women showed atrophic endometria in $95.7-97.9 \%$ of women and secretory changes in only $0-1.5 \% .{ }^{27}$ We can only speculate on the reasons for such a difference in the proportion of biopsies with secretory or atrophic changes compared with those in our study (secretory $26 \%$, atrophic $46 \%$ ), but the populations, regimens, and types of oestrogen and progestogen as well as the histopathologists were all different.

In the PEPI (postmenopausal estrogen-progestin interventions) trial, which lasted three years, 3.4\% of 352 women treated with sequential hormone replacement therapy developed simple hyperplasia and 1.7\% complex hyperplasia-this gives a total of $5.1 \%$ of women who developed hyperplasia over three years. ${ }^{12}$ In the group of women who received continuous combined hormone replacement therapy, one case of simple hyperplasia $(0.8 \%)$ occurred; the remaining 119 women had normal histological results at the end of three years. These findings are comparable with those of our preliminary study and the data presented here. ${ }^{2}$

Our findings compare favourably with those of Archer et al, who reported on endometrial histology in 801 perimenopausal and postmenopausal women without symptoms. ${ }^{28}$ Atrophic endometrial tissue was seen in $46.9 \%$ of women, proliferative changes in $16.7 \%$, secretory changes in $6.8 \%$, and hyperplasia in $5.2 \%$; cellular atypia and carcinoma were each seen in one case $(0.1 \%){ }^{28}$ Insufficient tissue was found in $24.5 \%$ of samples. In our findings, all endometrial tissue was histologically normal during long term continuous combined hormone replacement therapy, suggesting that this type of hormone replacement therapy may protect the endometrium from spontaneous abnormal changes from which untreated women are at risk.

\section{Meaning of the study}

Interest in the use of hormone replacement therapy has increased recently. Many women are considering

Table 4 Results of histological examination of endometrium at end of study or on withdrawal in women who had complex hyperplasia while taking hormone replacement therapy before the study. Values are number (percentage)

\begin{tabular}{lcc}
\multicolumn{2}{c}{ Time sample taken } \\
\hline Classification & At study completion $(\mathbf{n}=\mathbf{1 6})$ & On withdrawal $(\mathbf{n}=\mathbf{6})$ \\
\hline Unassessable & $4(25)$ & 0 \\
\hline Inactive or atrophic & $9(56)$ & $4(67)$ \\
\hline Secretory & $3(19)^{*}$ & $2(33)$ \\
\hline
\end{tabular}

*All women had a weakly secretory endometrium; includes one woman who had previously taken unopposed oestrogen. using such therapy over long periods to try to affect their long term health-particularly in relation to preventing osteoporosis. Women and their doctors need to be reassured that the long term use of hormone replacement therapy will not increase the risk of endometrial cancer, because recent reports showed that this risk may be increased after more than five years of use of sequential oestrogen and progestogen regimens (odds ratios 2.7 (95\% confidence interval 1.2 to 6.0 ) and 2.9 (1.8 to 4.6 ), respectively), ${ }^{3}$ but not with continuous combined hormone replacement therapy (0.2 (0.1 to 1.8)). The duration of progestogen treatment in each cycle in sequential regimens is critical: the risk of endometrial cancer is greater when progestogen is taken for less than 10 days. ${ }^{3}{ }^{29}$

In addition to the length of the progestogen phase, the dose and type of progestogen may be important factors. A recent study by Weiderpass and colleagues showed lower rates of endometrial cancer in women treated with continuous combined hormone replacement therapy that included a 19-nortestosterone derivative as the progestogen component than in women who took continuous combined hormone replacement therapy in which a 17-hydroxyprogesterone derivative was the progestogen component. A study in which women mainly took continuous combined conjugated oestrogens and 17-hydroxy-progesterone derivatives showed no differences in the incidence of endometrial cancer. ${ }^{29}$ The current study used a continuous combined preparation similar to that taken by most women in the study by Weiderpass et al. ${ }^{4}$ The reversal of endometrial hyperplasia (with no recurrence during five years of follow up) seen in our study may relate to this specific combination, which has a relatively strong progestogen component.

This is the largest and longest study of continuous combined hormone replacement therapy to date. In addition, our study is unique in that it includes women with endometrial hyperplasia. The findings of normal histology, together with the reversion of hyperplasia without cytological abnormality, suggest that continuous daily progestogen in such regimens provides greater protection of the endometrium and reassurance that long term treatment does not harm the endometrium.

\section{Unanswered questions and future research}

Despite the reassurance provided by our key results, studies of even longer duration are required. A trend towards the use of continuous combined hormone replacement therapies that include low doses of oestrogens-for example, $1 \mathrm{mg}$ oestradiol or its equivalent-and different combinations of hormones means that the safety of such regimens needs to be evaluated continually.

A recent short term study of continuous combined hormone replacement therapy with oestradiol $1 \mathrm{mg}$ and varying doses of norethisterone acetate over one year reported an incidence of endometrial hyperplasia of less than $1 \%{ }^{30}$ It would be interesting to establish whether the use of continuous combined hormone replacement therapy has a role in the treatment of complex hyperplasia arising in postmenopausal women not taking hormone replacement therapy. 


\section{What is already known on this topic}

Long term use of sequential oestrogen-progestogen hormone replacement therapy increases the risk of endometrial cancer

Continuous combined hormone replacement therapy regimens are safe and effective in the short term treatment of postmenopausal women

Previous trials have involved small numbers of patients $(<100)$ or short durations of treatment (2-3 years), or both

\section{What this study adds}

All women who had complex hyperplasia while taking sequential or unopposed hormone replacement therapies reverted to normal endometrial patterns

Continuous combined hormone replacement therapies that include continuous progestogen improve endometrial safety when used in the long term (up to five years)

This article describes the long term follow up to a study recently published in the British Journal of Obstetrics and Gynaecology. Other members of the UK Continuous Combined Study Investigators Group were A Bhalla (Bath), J McQueen (Beckenham), W Thompson (Belfast), D Heath (Birmingham), J Newton (Birmingham), D Pugh (Cardiff), R Wallace (County Armagh), I Smith (Coppull), J Lorimer (Durham), H McEwan (Glasgow), D McKay-Hart (Glasgow), T Wheatley (Haywards Heath), D McLintock (Welwyn Garden City), T Mahmood (Kirkcaldy), J Drife (Leeds), F Al-Azzawi (Leicester), A Breeson (Lincoln), W Francis (Liverpool), R Kirkman (Manchester), M Al Samarrai (Neath), G Filshie (Nottingham), D Barlow and M Rees (Oxford), S Randall (Portsmouth), J Elias-Jones (Redditch), S Drew (Rowlands Castle), M Paterson (Sheffield), J Wordsworth (Sheffield), R Fear and D Sturdee (Solihull), E Eyong (Stockport), P O'Brien (Stoke-on-Trent), and B Ruparelia (Worcester).

Contributors: All authors were members of the United Kingdom multicentre study advisory board. MW reported the histology and wrote the paper. DWS recruited most of the patients to the study and wrote the paper. LGU designed the initial study. KO'B coordinated and collated the data and wrote the paper. MJC provided advice on statistical analysis. DWS and MW will act as guarantors.

Funding: This study was sponsored by and carried out in collaboration with Novo Nordisk, Denmark, and Novo Nordisk, UK.

Competing interests: MW, DWS, DHB, LGU, MJC, and MPY have been paid by Novo Nordisk as members of the Kliofem steering committee. MW held a research consultancy with Novo Nordisk with respect to hormone replacement therapy. WLGU owns shares in Novo Nordisk and other pharmaceutical companies.

1 Sturdee DW, Barlow DH, Ulrich LG, Wells M, Gydesen H, Campbell M, et al. Is the timing of withdrawal bleeding a guide to endometrial safety during sequential oestrogen-progestagen replacement therapy? Lancet 1994:344:979-82.

2 Sturdee DW, Ulrich LG, Barlow DH, Wells M, Campbell MJ, Vessey MP, et al. The endometrial response to sequential and continuous combined oestrogen-progestogen replacement therapy. $\mathrm{Br} J$ Obstet Gynaecol 2000;107:1392-400.

3 Beresford SAA, Weiss NS, Voigt LF, McKnight B. Risk of endometrial cancer in relation to use of oestrogen combined with cyclic progestagen therapy in postmenopausal women. Lancet 1997;349:458-61.
4 Weiderpass E, Adami HO, Baron JA, Magnusson C, Bergstrom R, Lindgren A, et al. Risk of endometrial cancer following estrogen replacement with and without progestins. J Natl Cancer Inst 1999;91:1131-7.

5 Ravnikar VA. Barriers for taking long-term hormone replacement therapy: why do women not adhere to therapy? Eur Menopause J 1996;3:90-3.

6 Rees M. On menstrual bleeding with hormone replacement therapy. Lancet 1994:343:250.

7 Woodruff JD, Pickar JH, for the Menopause Study Group. Incidence of endometrial hyperplasia in postmenopausal women taking conjugated estrogens (Premarin) with medroxyprogesterone acetate or conjugated estrogens alone. Am J Obstet Gynecol 1994;170:1213-23.

8 Staland B. Continuous treatment with a combination of estrogen and gestagen - a way of avoiding endometrial stimulation. Clinical experiences with Kliogest. Acta Obstet Gynaecol Scand 1985;130(suppl):29-35.

9 Stadberg E, Mattsson LÅ, Uvebrant M. 17 beta-estradiol and norethisterone acetate in low doses as continuous combined. Maturitas 1996;23:31-9.

10 Udoff L, Langenberg P, Adashi EY. Combined continuous: a critical review. Obstet Gynecol 1995;86:306-16.

11 AinMelk Y. Comparison of two continuous combined estrogen progestogen regimens in postmenopausal women: a randomized trial. Fertil Steril 1996;66:962-8.

12 Writing Group for the PEPI Trial. Effects of hormone replacement therapy on endometrial histology in postmenopausal women. The postmenopausal estrogen/progestin interventions (PEPI) trial. JAMA 1996;275:370-5.

13 Perry W, Wiseman RA, Cullen NM. Combined oral estradiol valerate-norethisterone treatment over three years in postmenopausal women.1. Clinical aspects and endometrial histology. Gynaecol Endocr 1998;12:109-22

14 Obel EB, Munk-Jensen N, Svenstrup B, Bennett P, Micic S, Henrik-Nielsen R, et al. A two-year, double-blind controlled study of the clinical effect of combined and sequential postmenopausal replacement therapy and steroid metabolism during treatment. Maturitas 1993;16:1321

15 Mattsson L-Å, Cullberg G, Samsioe G. Evaluation of a continuou oestrogen-progestogen regimen for climacteric complaints. Maturitas 1982:4:95-102

16 Sporrong T, Hellgren M, Samsioe G, Mattsson L-Å. Comparison of four continuously administered progestogens plus estradiol combinations for climacteric complaints. Br J Obstet Gynaecol 1988;95:1042-8.

17 Hawthorn RJS, Spowart K, Walsh D, Hart DM. The endometrial status of women on long-term continuous combined hormone replacement therapy. Br J Obstet Gynaecol 1991;98:939-42.

18 Cornier E. The Pipelle. A disposable device for endometrial biopsy. Am J Obstet Gynecol 1994;148:109-10.

19 Leather AT, Savvas M, Studd JW. Endometrial histology and bleeding patterns after 8 years of continuous combined oestrogen and progestogen therapy in postmenopausal women. Obstet Gynecol 1991;78:1008-10.

20 Staland B. Continuous treatment with natural oestrogens and progestagens. A method to avoid endometrial stimulation. Maturitas 1981:3:145-56.

21 Hill DA, Weiss NS, Beresford SAA, Voigt LF, Daling JR, Stanford JL, et al. Continuous combined hormone replacement therapy and risk of endometrial cancer. Am J Obstet Gynecol 2000;183:1456-61.

22 McGonigle KF, Karlan BY, Barbutto DA, Leuchter RS, Lagasse LD, Judd HL. Development of endometrial cancer in women on estrogen and progestin. Gynecol Oncol 1994;55:126-32.

23 Comerci JT, Fields AL, Runowicz CD, Goldberg GL. Continuous low-dose combined hormone replacement therapy and the risk of endometrial cancer. Gynecol Oncol 1997;64:425-30.

24 Weinstein L, Bewtra C, Gallagher C. Evaluation of a continuous combined low-dose regimen of estrogen-progestin for treatment of the menopausal patient. Am J Obstet Gynecol 1990;162:1534-42.

25 Spowart KJM, Walsh DJ, Hawthorn RJS, Hart D. Hysteroscopic assessment of the effects of a continuous combined oestrogenprogestagen regimen on the endometrium of postmenopausal women. Gynaecol Endosc 1992;1:33-5.

26 Piegsa K, Calder A, Davis JA, McKay Hart D, Wells M, Bryden F. Endometrial status in post-menopausal women on long-term continuous combined (Kliofem $\left.{ }^{\circledR}\right)$ : a comparative study of endometrial biopsy, outpatient hysteroscopy and transvaginal ultrasound. Eur J Obstet Gynecol Reprod Biol 1997;72:175-80.

27 Nand SL, Webster MA, Baber R, O'Connor V, for the Ogen/Provera Study Group. Bleeding pattern and endometrial changes during continuous combined hormone replacement therapy. Obstet Gynecol 1998;91:678-84

28 Archer DF, McIntyre-Seltman K, Wilborn WW Jr, Dowling EA, Cone F, Creasy GW, et al. Endometrial morphology in asymptomatic postmenopausal women. Am J Obstet Gynecol 1991;165:317-22.

29 Pike MC, Peters RK, Cozen W, Probst-Hensch NM, Felix JC, Wan PC, et al. Estrogen-progestin replacement therapy and endometrial cancer. J Nat Cancer Inst 1997;89:1110-6.

30 Kurman RJ, Felix JC, Archer DF, Nanavati N, Arce J-C, Moyer DL. Norethindrone acetate and estradiol-induced endometrial hyperplasia. Obstet Gynecol 2000;96:373-9.

(Accepted 3 December 2002) 